\title{
Evaluation of anthropometric equations developed to estimate neonates' body composition: a systematic review
}

\author{
Avaliação de equações antropométricas desenvolvidas para estimar \\ a composição corporal de neonatos: uma revisão sistemática
}

Daniele Marano (https://orcid.org/0000-0001-6985-941X) ${ }^{1}$

Elissa Costa de Oliveira (https://orcid.org/0000-0002-7771-658X) ${ }^{2}$

Yasmin Notarbartolo de Villarosa do Amaral (https://orcid.org/0000-0001-8159-0564) ${ }^{3}$

Leila Maria Lopes da Silva (https://orcid.org/0000-0001-6275-8392) ${ }^{1}$

Maria Elisabeth Lopes Moreira (https://orcid.org/0000-0002-2034-0294) ${ }^{1}$

${ }^{1}$ Unidade de Pesquisa Clínica, Instituto Nacional de Saúde da Mulher, da Criança e do Adolescente Fernandes Figueira (IFF). Fundação Oswaldo Cruz (Fiocruz). Av. Rui Barbosa 716, Flamengo. 22250-020 Rio de Janeiro RJ Brasil. danielemarano@ yahoo.com.br ${ }^{2}$ Programa Institucional de Bolsa de Iniciação Científica (PIBIC). Fiocruz. Rio de Janeiro RJ Brasil.

${ }^{3}$ Programa de PósGraduação de Pesquisa Aplicada, IFF, Fiocruz. Rio de Janeiro RJ Brasil.

\begin{abstract}
This article aims to evaluate the anthropometric equations developed by selected studies in order to estimate the body composition of neonates. The systematic review consisted in the research of published articles in the following databases: PubMed, Brazilian Virtual Health Library, Embase and ScienceDirect by utilizing the following descriptors: "fat mass, fat free mass, anthropometry, air displacement plethysmography, validation, neonate". For doing so, the PRISMA protocol has been utilized. The bibliographical research resulted in 181 articles. However, only eight were selected for the present review because repetition in different databases and having been performed in adults, during pregnancy, in athletes, in preterm and children. There was discrepancy in terms of study method, mainly over the variables of the anthropometric equations, age and ethnicity of the neonates. All studies used the plethysmography method as a reference apart from one study. Only four studies had their equations validated. The studies that developed anthropometric models for estimating the body composition of neonates are scarce, and the use of these equations needs to be conducted carefully in order to avoid errors in nutritional diagnosis.
\end{abstract}

Key words Neonates, Fat-free mass, Fat mass, Plethysmography, Systematic review
Resumo Este artigo tem por objetivo avaliar as equações antropométricas desenvolvidas pelos estudos selecionados para estimar a composição corporal de neonatos. A revisão sistemática consistiu na busca de artigos publicados nas bases de dados PubMed, Biblioteca Virtual de Saúde, Embase e ScienceDirect utilizando os seguintes descritores: "fat mass, fat free mass, anthropometry, air displacement plethysmography, validation, neonate". Para isso foi utilizado o protocolo PRISMA. A busca bibliográfica resultou em 181 artigos. Entretanto, apenas oito foram selecionados para compor a presente revisão por estarem presentes em outras bases de dados, por terem sido realizados com adultos, atletas, prematuros e crianças. Houve discrepância em relação aos métodos dos estudos, sobretudo no que diz respeito as variáveis que compuseram as equações antropométricas. Com exceção de um artigo, todos utilizaram a pletismografia como método de referência. Apenas quatro estudos tiveram suas equações validadas. Além de serem escassos os estudos que desenvolveram equações antropométricos para estimar a composição corporal de neonatos, o uso desses modelos deve ser realizado com cautela para evitar erros no diagnóstico nutricional dos neonatos.

Palavras-chave Neonatos, Massa livre de gordura, Massa de gordura, Pletismografia, Revisão sistemática 


\section{Introduction}

Evaluation of body composition in newborns is extremely important to understand how fetal exposure to nutrients, hormones and environmental factors can impact the nutritional status in childhood and adulthood, allow the understanding of the changes that occur with development and growth, as well as the development of future metabolic diseases ${ }^{1,2}$.

There are numerous methods used to measure neonatal body composition that are classified as direct (corpse dissection), indirect (dual-energy X-ray absorptiometry (DXA), quantitative nuclear magnetic resonance and air-displacement plethysmography) and double-indirect (electrical bioimpedance, skinfold and perimeter measurements). It should be noted that in neonates a large part of these methods cannot be used due to the high cost of devices, the presence of radiation and the difficult transportation of instruments which are impractical to use in large population studies and often located in research laboratories ${ }^{1-3}$.

Due to limitations in the use of certain methods to evaluate body composition in neonates, some studies have developed anthropometric models over the years to measure body composition using plethysmography as a reference technique, as it is considered accurate in neonates ${ }^{3,4}$.

Development of an anthropometric model for neonates to estimate body composition by using devices more common in clinical practice such as scales, stadiometers and/or picometers, in comparison to accurate methods, is extremely important for health professionals in clinical practice, as they make it possible to assess these children's nutritional composition ${ }^{5}$.

Therefore, the present proposal aims to evaluate anthropometric equations developed by the selected studies to conduct a systematic review for estimating neonates' body composition.

\section{Methods}

Systematic review of the literature was performed, which consisted of a retrospective search of scientific articles developing anthropometric models to evaluate neonates' body composition using indicators such as skinfolds, weight, length, gender, among other reference methods.

The following bibliographic bases have been used: PubMed (free search engine), Brazilian Virtual Health Library (BVS, in the Portuguese abbreviation), Embase, ScienceDirect. The search for the articles began in April and ended in May 2018. It was carried out by two researchers independently. There was no divergence between the researchers while choosing the articles. The following descriptors were used in the search strategy: "fat mass, anthropometry, air displacement plethysmography, validation, neonate" or "fat mass, fat-free mass, anthropometry, air displacement plethysmography, validation" or "fat mass, fat-free mass, anthropometry, air displacement plethysmography, validation, neonates". For doing so, the Preferred Reporting Items for Systematic reviews and Meta-Analyses (PRISMA) protocol were used ${ }^{6}$.

The bibliographic search, according to the strategy established, resulted in 181 articles. In the BVS database, 18 articles were found. However, after reading the abstracts, no article was selected, as nine were present in other databases and five studies developed models for adults. 41 articles were found in the PubMed database, out of which four were selected. In the Science of Direct database, 107 articles were found, from which none was selected, and in the Embase database, 15 articles were found. Out of these, two were selected and two other articles were found in the references of one of the selected articles. Thus, only eight articles were selected to make up this present article. The main reasons for excluding studies were: repetition in different databases, and having been performed in adults, during pregnancy, in athletes, and in preterm and older children.

A checklist with 27 items was used, as well as a four-step flowchart recommended by PRISMA for helping authors to improve on their reporting of systematic reviews. Thus, a summary of each stage of the article selection process that made up this systematic review can be seen in the Figure 1.

Regarding the selection of articles, there was no restriction in terms of publication period or language. They were compared through the following axes: year of publication, sample size, type of study, objectives, ethnic groups, variables that made up the anthropometric model, anthropometric model formula and main results.

\section{Results}

According to the strategy established, the bibliographic search resulted in 181 articles for the present systematic review. However, only eight were selected for the following reasons: duplicat- 


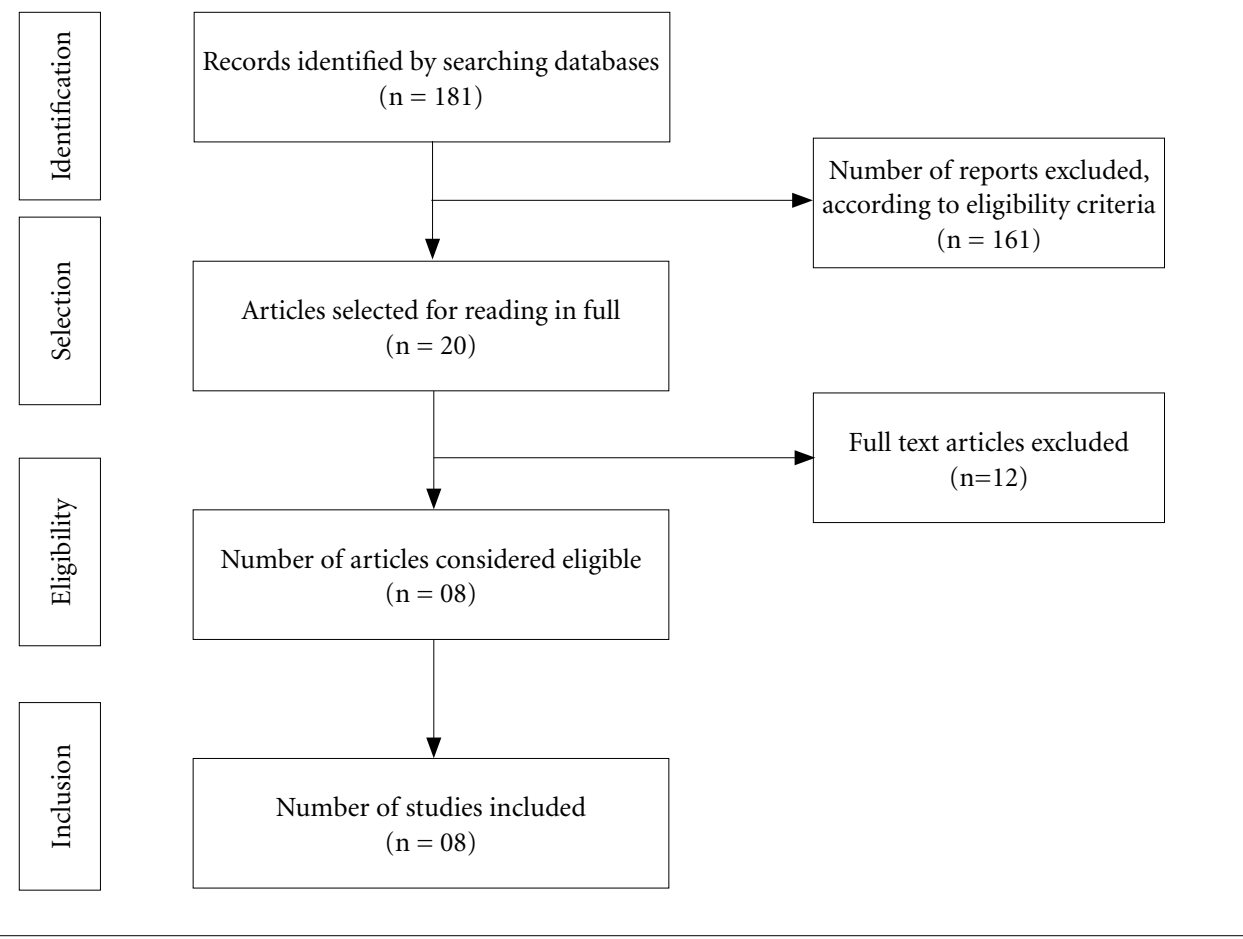

Figure 1. Flow of the selection process of the articles selected - PRISMA.

ed in other databases and/or samples containing adults, pregnant women, athletes, preterm and children.

One study aimed to predict fat free mass while five did so for fat free mass, and two evaluated both. Regarding the design employed, five carried out a cohort-type study and three ones carried out a cross-sectional study. Information on follow-up losses was obtained in all studies.

All studies used the plethysmography method as a reference apart from one study conducted by Catalano et al. ${ }^{7}$. Factors that made up anthropometric models varied, with weight, gender and length insertion remaining unanimous in the formulas to estimate body composition.

Regarding ethnicity as a factor associated with body composition, three studies worked with multiethnic samples and only one study included this variable in the anthropometric model.

\section{Discussion}

Excessive adiposity is a major risk factor for adverse health conditions and chronic diseases. Body fat assessment in infants is not only an im- portant nutritional indicator, but it is also considered to be a significant factor in health during adult life ${ }^{1,8}$.

In order to perform an anthropometric evaluation in children, weight and height/length indicators are often used to make up the following anthropometric indexes: weight for age, weight for length, length for age, body mass index for age $^{9,10}$. Although they are widely used in health professionals' clinical practices, these indicators cannot measure body composition (fat mass and fat-free mass) in neonates. Therefore, to evaluate body composition, it is necessary to use certain methods that are often not suitable for use in neonates because of the presence of radioactivity (Dual-energy X-ray absorptiometry [DXA, previously DEXA]), high cost, difficulties in device portability (air displacement plethysmography) behavioral requirements from the child during the evaluation (magnetic resonance) $)^{1,11}$.

The air displacement plethysmography applies basic gas laws to determine the body volume from that of the air displaced by the infant in an enclosed chamber, maintained at a constant temperature. Together with the weight measurement from the PEA POD scales, the density of 
the subject can be determined and, assuming a two-compartment model and constant density for fat and fat-free mass, the weight of each component can be determined ${ }^{4}$. This is a valid technique for assessing infant body composition and was validated against the gold standard 4 compartment model $(4 \mathrm{C})^{12}$ and against total body water using deuterium dilution ${ }^{13}$. No differences were found for percentage body fat when compared to the 4C model or total body water ${ }^{12,13}$.

Therefore, some studies over the years have developed anthropometric models to estimate body composition using accurate methods such as plethysmography as a reference, which serve as parameters for choosing the indicators measured by devices available in health professionals' clinical practices (scales, stadiometers and picometers) $)^{5,14}$.

Anthropometric models in neonates using skinfolds were initially developed in 1977 by Dauncey et al. ${ }^{15}$ and in 1989 by Westrate \& Deurenberg ${ }^{16}$. However, these models were constructed based on theoretical body composition equations and were validated by Kulkarni et al. ${ }^{17}$ in infants 6-18 months old ${ }^{2}$. Catalano et al. ${ }^{7}$ have developed an anthropometric model to estimate neonatal fat mass by comparing total body electrical conductivity data with weight, length, and suprailium and tricipital skinfolds. Schmelzle \& Fusch ${ }^{18}$ have also developed anthropometric models to estimate neonatal fat mass by comparing data from the use of Dual-energy X-ray absorptiometry (DXA, previously DEXA) with the sum of four cutaneous skinfolds (tricipital, bicipital, suprailium and subscapular) and length.

Although the first studies that formulated anthropometric models were developed a considerable time ago, it can be observed that there are still few studies that have developed models to evaluate body composition in neonates. It should be noted that the great majority of studies found in the databases that were part of this systematic review formulated equations for adults, athletes, preterm and older children. Another relevant piece of information concerns the disparity between results found due to differences between the methods used with regard to type of mass evaluated (fat mass and/or fat-free mass), indicators that made up the final anthropometric models, anthropometric evaluation and body composition employed, and different ethnicities of the subjects evaluated.

Regarding the prediction of fat mass and/or fat-free mass, Catalano et al. ${ }^{7}$ and Aris et al. ${ }^{8}$ have evaluated fat mass in 194 and 88 children with
1-3 days, respectively. Deierlein et al. ${ }^{14}$ have conducted a study with 128 children born at term and of adequate birth weight with the objective of developing an anthropometric model to predict neonatal fat mass. Tint et al. ${ }^{1}$, in a cohort of 173 infants, aimed to develop an equation for evaluating the amount of fat-free mass. Lingwood et al. ${ }^{11}$ and Wibæk et al. ${ }^{5}$ have evaluated both fatfree mass and fat mass in 77 and 101 children, respectively. Huvanandana et al. ${ }^{4}$ have conducted a study with 504 neonates with the objective of developing an anthropometric model to predict low and high fat mass neonates.

It must be stressed that there has been disparity between the studies regarding insertion of different indicators to make up the anthropometric models. Catalano et al. ${ }^{7}$ have used birth weight, flank skinfold and length. Deierlein et al. ${ }^{14}$ have used the following indicators: gender, race, gestational age, weight, height, waist circumference, triceps skinfolds, subscapularis and thigh. The authors have observed that the anthropometric model developed in this study was able to explain $81 \%$ of the neonatal fat mass variance. This value was slightly lower than the determination coefficients of other studies ${ }^{7}$. Lingwood et al. ${ }^{11}$ have developed fat-free predictive models for each phase of the study by using weight, gender, length and impedance index for infants older than three months. Aris et al. ${ }^{8}$ have included weight, gender, gestational age and subscapular skinfold. This model estimated neonatal fat mass with a coefficient of determination of $81.1 \%$. In this study triceps skinfold was not a significant predictor, but subscapular skinfold was. According to authors, this might be due to greater within-subject variability for triceps measurements as observed in this study group. Wibæk et al..$^{5}$ have used weight, length, age, gender and impedance index. However, they have observed that length has not presented correlation with mass prediction. Therefore, it was excluded from the final model. The model explained $95 \%$ of the variance of the neonatal fat mass. Tint et al. ${ }^{1}$ have developed two anthropometric models including variables gender, weight and length, and another model containing these variables with the addition of resistance to the use of bioelectrical impedance analysis (BIA). Huvanandana et al. ${ }^{4}$ have developed two anthropometric models to estimate low and height fat mass. The low models containing weight, length and chest circumference and the height included weight, length, birthweight and head circumference. This study includes the large sample size of neonates, but the models may be 
improved if adjusted for additional features such as skinfold measurements, which were not collected in this dataset.

It's noteworthy that all equations were developed in newborns ranging in age from zero to four days old. According to Cauble et al. ${ }^{2}$, there is a track record for studies that uses equations that have been developed in one age group and then validated in another age group or equations are used in age groups where they were not developed or validated. Therefore, the study's purpose was to validate Deierlein et al. ${ }^{14}$, Catalano et al. ${ }^{7}$, Lingwood et al. ${ }^{11}$ and Aris et al. ${ }^{8}$ infant anthropometric equations at birth and within three months in comparison to body fat measured using air displacement plethysmography. At birth, this suggested that the Catalano et al. ${ }^{7}$, Lingwood et al. ${ }^{11}$ equations overestimated fat mass at lower fat mass values and underestimated fat mass values for greater mass values.

For the Deierlein et al. ${ }^{14}$ and Aris et al. ${ }^{8}$ equation, no bias was detected. Comparing these results with other studies that validated these infant prediction equations in 2014, Catalano et al. ${ }^{19}$ validated the Catalano et al. ${ }^{7}$ equation in a sample of newborns not used to develop the equation. They reported a better correlation than was found in this study $\left(\mathrm{R}^{2}=0.69\right.$ vs 0.55$)$. The Deierlein et al. ${ }^{14}$ equation has never been validated and the Aris et al. ${ }^{8}$ and Lingwood et al. ${ }^{11}$ equations have only been cross-validated. According to other authors, such results may be partially explained by the fact that the period of early infancy presents rapid infant growth with a wide range of inter-individual variability. A range of infant growth exists due to gender differences and to the infant feeding method (formula vs. breastfeeding). It can be stressed that none of the prediction equations for infants validated included feeding method as a predictive variable, likely because they were developed in 0-4 days old newborns.

Regarding the equipment used to measure body composition, Lingwood et al. ${ }^{11}$, Wibæk et al. ${ }^{5}$ and Tint et al. ${ }^{1}$ used bioelectrical impedance analysis and air displacement plethysmography. Deierlein et al. ${ }^{14}$, Aris et al. ${ }^{8}$ and Huvanandana et al. ${ }^{4}$ used only air displacement plethysmography. Despite the study of Catalano et al. ${ }^{7}$ not having used plethysmography as a reference method, it has been included in this systematic review since the use of plethysmography has been validated in the study conducted by Cauble et al. ${ }^{2}$.

It is worth stressing the unanimity among the authors ${ }^{1,5,11}$ in assessing that bioelectrical impedance analysis was not considered an adequate method to evaluate body composition in children below three months of age. However, in children older than three months the insertion of resistance from bioelectrical impedance analysis increased the prediction of the model to evaluate fat-free mass and/or fat mass. These findings can be partially explained as follows: the use of bioelectrical impedance analysis to estimate fat-free mass is based on the assumption that adipose tissue is essentially nonconductive. However, in the embryo and in the newborn adipose tissue has a vast vascular supply ${ }^{3}$. In addition, the percentage of water in the newborn is around 45$48 \%$. Therefore, this increase in adipose tissue vascularization and high water content in the first months of life may increase the conductivity of fat, making it impossible to use bioelectrical impedance analysis as a predictor of fat-free mass $^{5,11,20}$.

Use of air displacement plethysmography as a reference method to compare with results of bioelectrical impedance analysis, weight, length and/ or skinfolds was an egalitarian issue among the studies selected. This method evaluates volume and body density by measuring the volume of air displaced by the body within a closed chamber. Air displacement plethysmography is relatively recent, fast, safe, comfortable and can be used in newborns ${ }^{20,21}$. This technique is based on Boyle's law, which is based on the inverse relationship between pressure and volume to determine body composition. Once this volume is defined, it is possible to apply principles of densitometry to determine body composition by calculating body density $^{22}$. Some negative aspects of this method are the device size and high cost, which make it unfeasible in clinical practice ${ }^{1,23}$.

Regarding the possible determinants of body composition, the only one that was included was ethnicity ${ }^{24,25}$. The study conducted by Deierlein et al. ${ }^{14}$ consisted of a multiethnic sample $(42 \%$ Caucasian, 6\% African American, 20\% Hispanic, $10 \%$ Asian, and $22 \%$ other) and ethnicity was entered into the model. The populations used to develop the other equations were the following: Catalano et al. ${ }^{7}$ was primarily Caucasian (64\%) and data were collected in the United States. The Lingwood et al. ${ }^{11}$ equation was developed from an Australian sample that was $89 \%$ Caucasian, and the Aris et al. ${ }^{8}$ sample was an Asian population from Singapore that was comprised of Chinese, Malay, and Indian newborns ${ }^{8}$.

As for the cohort conducted by Tint et al. ${ }^{1}$, it was made up of a homogeneous sample of Asians, 


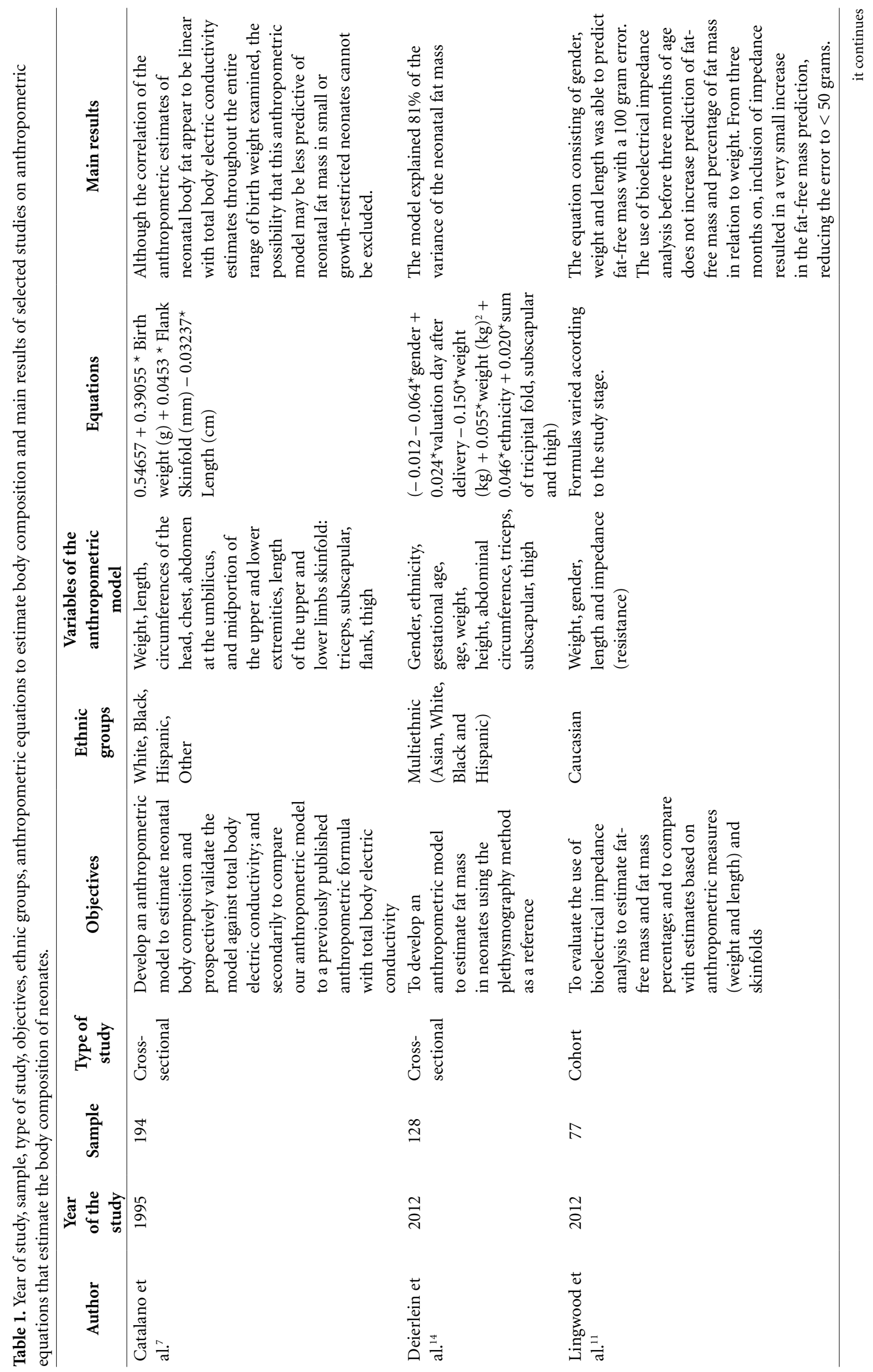




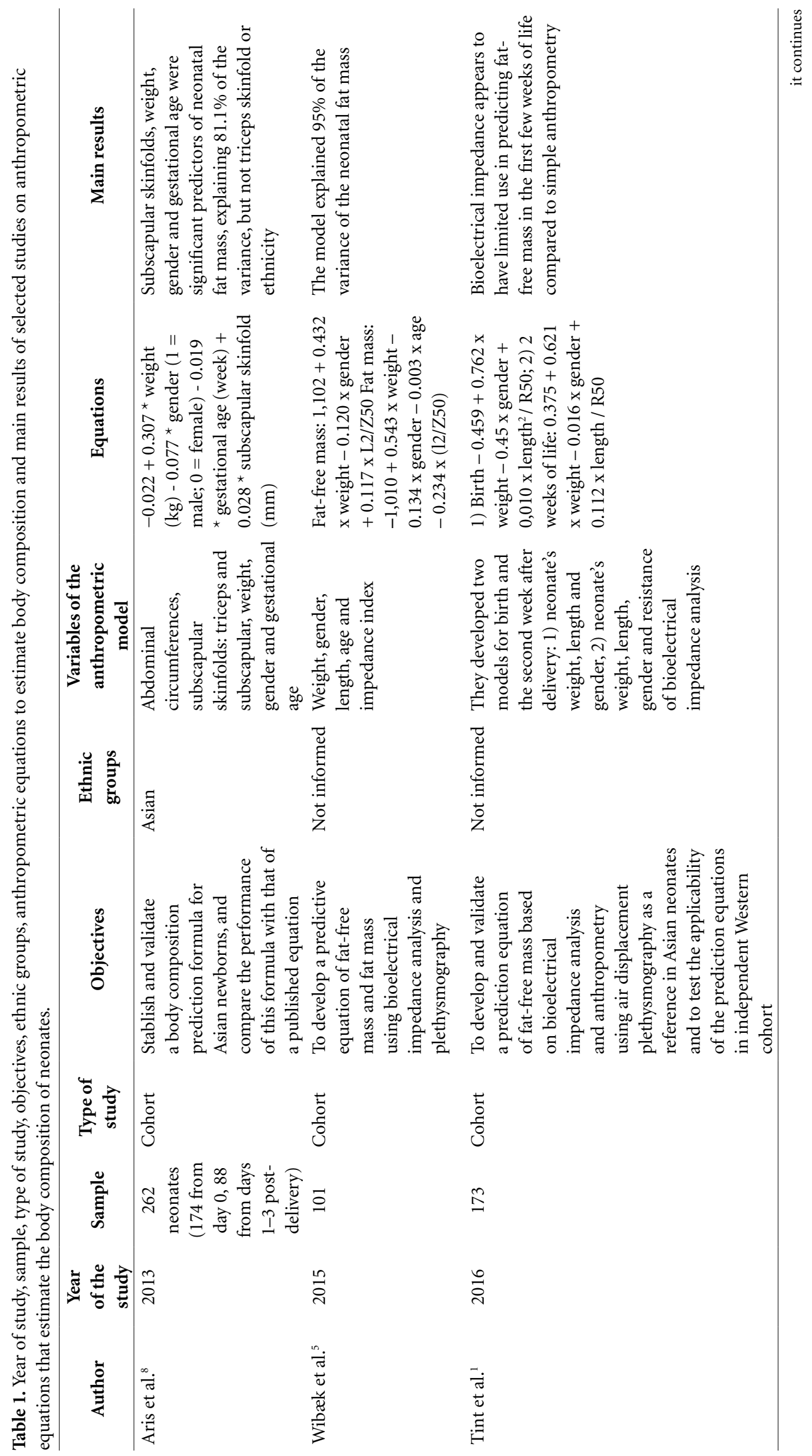




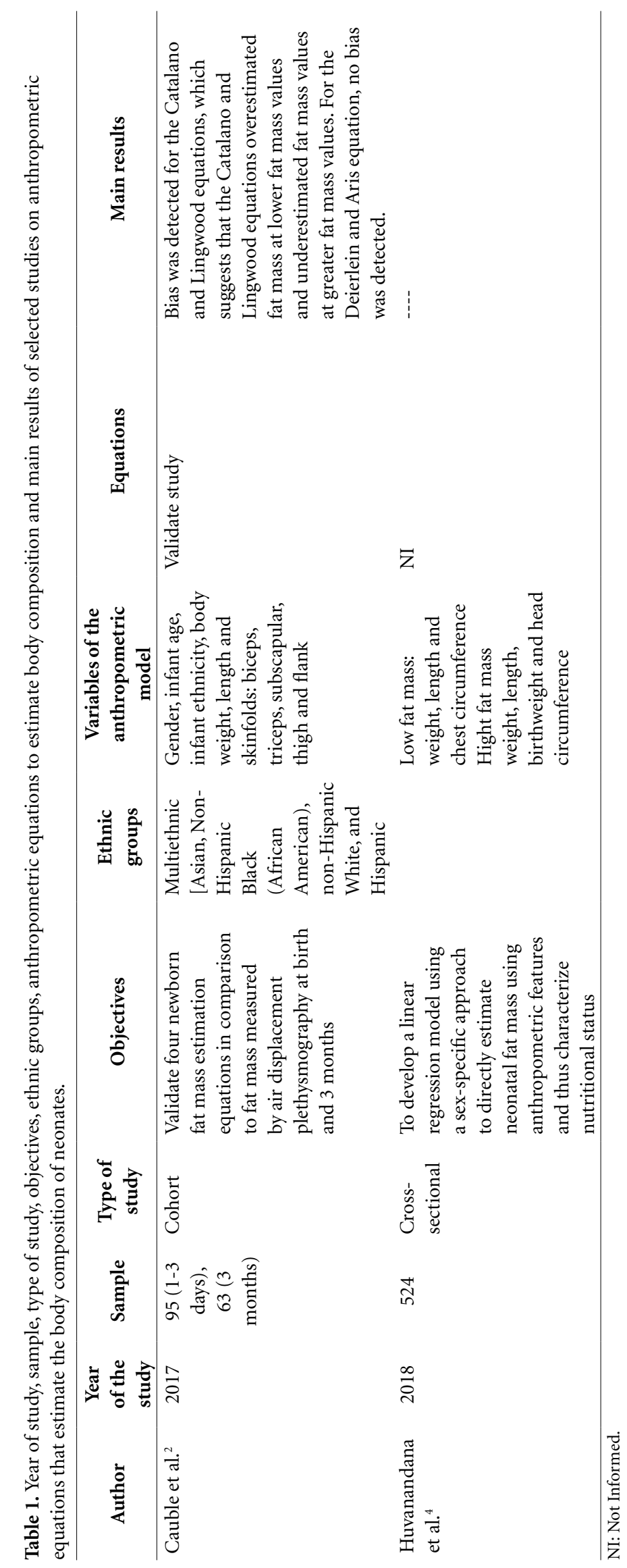


and it also applied this equation in a sample of Western neonates. A very interesting fact that the authors observed is that for the Asian sample, length and resistance were predictors of fat-free mass between the first and second weeks of age. As for Western populations, both length and resistance were not predictors of fat-free mass until four months of life. According to the authors, the main difference among the ethnic groups being the hydration level between Asian and Western populations. Therefore, these differences among populations confirm that ethnicity is an important determinant of body composition to be investigated in studies dealing with this issue. Wibæk et al..$^{5}$ emphasize that future research should aim to validate the equations developed in other population groups. However, Aris et al. ${ }^{8}$ evaluated ethnicity was also not a significant contributor in predicting neonatal fat mass. The lack of contribution of ethnicity in the prediction of body fat is also consistent with earlier literature on adult Singaporean Chinese, Malays and Indians, which had noted a similar observation ${ }^{26,27}$.

Regarding the age of neonates that were evaluated for the development of the predictive equations for fat mass and/or fat-free mass, it has been observed that the studies of Deirlein et al. ${ }^{14}$, Catalano et al. ${ }^{7}$ and Aris et al. ${ }^{8}$ derived from infants whose measurements were taken on days 1-3 and excluded infants whose measurements were tak- en on day 0 . The study conducted by Wibæk et al. ${ }^{5}$ and Tint et al. ${ }^{1}$, however, included children 48 hours and 0 to 3 days after birth, respectively. It is necessary to consider this data challenging due to rapid changes in body fluids in the first days of life. Which results in a reduction of 5 to $10 \%$ of body weight and subsequent change in body composition and water volume ${ }^{1,8}$.

Mainly due to the methodological differences among the articles selected to make up this review, especially in terms of the indicators that make up the anthropometric equations, the age and ethnicity were the main factors evaluated. Another noteworthy point is that no validation studies were found for three of the selected articles $^{1,4,5}$. The remaining ones ${ }^{7,8,11,14}$ have been recently validated by Cauble et al. ${ }^{2}$, who demonstrated that these anthropometric equations should be used carefully in order to avoid erroneous conclusions in determining the body composition of neonates.

In addition, it was possible to observe that there are still few studies that have developed anthropometric models to estimate fat mass and/or fat-free mass during early childhood. Therefore, it is of extreme importance that new studies be carried out with the objective of constructing validated anthropometric models for newborns that provide qualified care from health professionals based on apparatuses available in clinical practices.

\section{Collaborations}

D Marano participated in the design, methodological design, analysis and interpretation of data and writing of the article. EC Ooliveira participated in the design, methodological design, data analysis and interpretation, final article writing. YNV Amaral participated in data analysis and article writing. LML Silva participated in data analysis and article writing. MEL Moreira participated in the analysis, interpretation of data and approval of the version to be published.

\section{References}

1. Tint MT, Ward LC, Soh SE, Aris IM, Chinnadurai A, Saw SM, Gluckman PD, Godfrey KM, Chong YS, Kramer MS, Yap F, Lingwood B, Lee YS. Estimation of fat-free mass in Asian neonates using bioelectrical impedance analysis. Br J Nutr 2016; 115(6):1033-1042.

2. Cauble JS, Dewi M, Hull HR. Validity of anthropometric equations to estimate infant fat mass at birth and in early infancy. BMC Pediatrics 2017; 17:1-8.

3. Gridneva Z, Hepworth AR, Ward LC, Lai CT, Hartmann PE, Geddes DT. Determinants of body composition in breastfed infants using bioimpedance spectroscopy and ultrasound skinfolds - methods comparison. Pediatr Res 2017; 81(3):423-433.

4. Huvanandana J, Carberry AE, Turner RM, Bek EJ, Raynes-Greenow $\mathrm{CH}$, McEwan AL, Jeffery HE. An anthropometric approach to characterising neonatal morbidity and body composition, using air displacement plethysmography as a criterion method. PLoS One 2018; 13(3):e0195193. 
5. Wibæk R, Kæstel P, Skov SR, Christensen DL, Girma T, Wells JC, Friis H, Andersen GS. Calibration of bioelectrical impedance analysis for body composition assessment in Ethiopian infants using air-displacement plethysmography. Eur J Clin Nutr 2015; 69(10):10991104.

6. Moher D, Liberati A, Tetzlaff J, Altman DG. PRISMA Group. Preferred reporting items for systematic reviews and meta-analyses: the PRISMA statement. PLoS Med 2009; 6(7):e1000097.

7. Catalano PM, Thomas AJ, Avallone DA, Amini SB. Anthropometric estimation of neonatal body composition. Am J Obstet Gynecol 1995; 173(4):1176-1181.

8. Aris IM, Soh SE, Tint MT, Liang S, Chinnadurai A, Saw SM, Kwek K, Godfrey KM, Gluckman PD, Chong YS, Yap FK, Lee YS. Body fat in Singaporean infants: development of body fat prediction equations in Asian newborns. Eur J Clin Nutr 2013; 67(9):922-927.

9. World Health Organization (WHO). Child growth standards: length/height-for-age, weight-for-age, weightfor-length, weight-for-height and body mass index-for-age: methods and development. Geneva: WHO; 2006.

10. World Health Organization (WHO). Child growth standards: length/height-for-age, weight-for-age, weightfor-length, weight-for-height and body mass index-for-age: methods and development. Geneva: WHO; 2007.

11. Lingwood BE, Storm van Leeuwen AM, Carberry AE, Fitzgerald EC, Callaway LK, Colditz PB, Ward LC. Prediction of fat-free mass and percentage of body fat in neonates using bioelectrical impedance analysis and anthropometric measures: validation against the PEA POD. British J Nutr 2012; 107(10):1545-1552.

12. Ellis KJ. Evaluation of body composition in neonates and infants. Semin Fetal Neonatal Med 2007; 12(1):8791.

13. Ma G, Yao M, Liu Y, Lin A, Zou H, Urlando A, Wong WW, Nommsen-Rivers L, Dewey KG. Validation of a new pediatric air-displacement plethysmograph for assessing body composition in infants. Am J Clin Nutr 2004; 79(4):653-660.

14. Deierlein AL, Thornton J, Hull H, Paley C, Gallagher D. An anthropometric model to estimate neonatal fat mass using air displacement plethysmography. Nutr Metab (Lond) 2012; 9:21.

15. Dauncey MJ, Gandy G, Gairdner D. Assessment of total body fat in infancy from skinfold thickness measurements. Arch Dis Child 1977; 52(3):223-227.

16. Westrate JA, Deurenberg P. Body composition in children: proposal for a method for calculating body fat percentage from total body density or skinfold-thickness measurements. Am J Clin Nutr 1989; 50(5):1104-1115.

17. Kulkarni B, Mamidi RS, Balakrishna N, Radhakrishna $\mathrm{KV}$. Body composition assessment in infancy and early childhood: comparison of anthropometry with dual-energy X-ray absorptiometry in low-income group children from India. Eur J Clin Nutr 2014; 68(6):658663.

18. Schmelzle HR, Fusch C. Body fat in neonates and young infants: validation of skinfold thickness versus dual-energy X-ray absorptiometry. Am J Clin Nutr 2002; 76(5):1096-1100.
19. Catalano PM, Mele L, Landon MB, Ramin SM, Reddy UM, Casey B, Wapner RJ, Varner MW, Rouse DJ, Thorp Jr JM, Saade G, Sorokin Y, Peaceman AM, Tolosa JE. Inadequate weight gain in overweight and obese pregnant women: what is the effect on fetal growth? Am J Obstet Gynecol 2014; 211(2):137.e1-7.

20. Villar J, Puglia FA, Fenton TR, Ismail LC, Staines-Urias E, Giuliani F, Ohuma EO, Victora CG, Sullivan P, Barros FC, Lambert A, Papageorghiou AT, Ochieng R, Jaffer YA, Altman DG, Noble AJ, Gravett MG, Purwar M, Pang R, Uauy R, Kennedy SH, Bhutta ZA. Body composition at birth and its relationship with neonatal anthropometric ratios: the newborn body composition study of the INTERGROWTH-21st project. Pediatr Res 2017; 82(2):305-316.

21. Fields DA, Goran MI, McCrory MA. Body composition assessment via air-displacement plethysmography in adults and children: a review. Am J Clin Nutr 2002; 75(3):453-467.

22. Mello MT, Dâmaso AR, Antunes HK, Siqueira KO, Castro ML, Bertolino SV, Stella SG, Tufik S. Avaliação da composição corporal em adolescentes obesos: o uso de dois diferentes métodos. Rev Bras Med Esporte 2005;11(5):267-270.

23. Strydom K, Niekerk EV, Dhansay MA. Factors affecting body composition in preterm infants: Assessment techniques and nutritional interventions. Pediatr $\mathrm{Ne}$ onatol 2019; 60(2):121-128.

24. Sletner L, Nakstad B, Yajnik CS, Mørkrid K, Vangen S, Vårdal MH, Holme IM, Birkeland KI, Jenum AK. Ethnic differences in neonatal body composition in a multiethnic population and the impact of parental factors: a population-based cohort study. PLoS One 2013; 8(8):e73058.

25. Paley C, Hull H, Ji Y, Toro-Ramos T, Thornton J, Bauer J, Matthews P, Yu A, Navder K, Dorsey K, Gallagher D. Body fat differences by self-reported race/ethnicity in healthy term newborns. Pediatr Obes 2016; 11(5):361-368.

26. Deurenberg P, Deurenberg-Yap M. Validity of predicted body fat from skinfolds in Singaporean Chinese, Malays and Indians. Int J Body Comp Res 2003; 1:2330.

27. Deurenberg-Yap M, Ng SA, Foo LL, Deurenberg P. Development and validation of a prediction equation for body fat percent based on skinfolds in Singaporean adults and adolescents. Int J Body Comp Res 2003; 1:103-109.

Article submitted 21/02/2018

Approved 06/10/2018

Final version submitted 08/10/2018 